\title{
DISTRICT HEATING SYSTEM: EVALUATION OF ENVIRONMENTAL AND ECONOMIC ASPECTS
}

\author{
M. RAVINA, D. PANEPINTO \& M. ZANETTI \\ Politecnico di Torino, DIATI Department, Italy
}

\begin{abstract}
With the need for limiting pollutant emissions, careful management of energy plants should be considered to reduce the footprints that can be caused by these systems. Advantages of district heating (DH) systems have been linked to a decrease in local and global emissions, centralized heat production located outside urban centres, possible utilization of renewable heat sources.

District heating, consisting of the distribution of hot water by means of underground networks for the buildings' heating and sanitary water, is an ever-expanding technology that allows the optimization of energy resources, with positive consequences in terms of both economic savings and environmental impacts.

The aim of this work is to analyse the district heating system from an environmental point of view, in way to realize a general procedure of evaluation. To this end, the Italian city of Turin is taken as case study. Turin has long been subject to high concentration levels of pollutants, especially $\mathrm{NO}_{\mathrm{x}}$ and particulate. The environmental compatibility of extending the district heating network is evaluated. Two different tools are used: first, the environmental balance is defined to perform an evaluation of the flux modification at the emission sources; secondly, the atmospheric impacts of emissions are estimated using CALPUFF dispersion model. The results show a future reduction in overall $\mathrm{NO}_{\mathrm{x}}$ emission, as well as a reduction of ground level average $\mathrm{NO}_{\mathrm{x}}$ concentration ranging between 0.2 and $4 \mu \mathrm{g} / \mathrm{m}^{3}$. This study provides important information on the effects of a change of the energy configuration on air quality in an urban area. The proposed comprehensive methodology is applicable for other similar cases.

Keywords: district heating system, environmental evaluation, mass balance, $\mathrm{NO} \mathrm{x}_{x}$, pollutant dispersion model
\end{abstract}

\section{INTRODUCTION}

District heating $(\mathrm{DH})$ is a technology used for supplying a town district or a complete town with the heat generated in large production plants. By concentrating and scaling up the heat production instead of using single house boilers, a lower specific heat production cost can be obtained as well as a higher conversion efficiency and the possibility to co-generate electricity. DH networks are commonly proposed in previous works as an environmentally friendly solution for providing heating services for the built environment due to their multiple benefits, such as centralized heat, production located outside urban centres, possible utilization or renewable heat sources and increased comfort for the consumers.

The use of combined heat and power (CHP) systems in DH is an increasingly popular solution to meet the thermal energy needs in urban areas. Large DH networks are usually powered by large plants implementing a combined cycle. These systems are usually fuelled by natural gas.

The environmental analysis of generation plants connected to DH networks is crucial, as these are usually located in heavily populated urban areas, characterized by the combined contributions of different emission sources, such as traffic, industrial and residential activities. District heating networks are commonly proposed in previous works as an environmentally friendly solution for providing heating services for the built environment due to their multiple benefits, such as centralized heat, production located outside urban centres, possible utilization or renewable heat sources and increased comfort for the consumers. 
By analysing the existing scientific production, many works concerning different aspects of DH are found. Lake et al. [1], for example, studied the implementation of district heating and cooling systems across a broad set of case studies previously reported in papers. Topics addressed include their history, system identification, energy sources, design considerations, environmental impacts, economic feasibility, performance analysis and the role of energy policy.

From the environmental point of view, numerous studies have been conducted on emissions associated with the operation of cogeneration plants for DH. The characterization of emissions interests both the global level, by assessing the overall contribution to the greenhouse effect, and the local level, identifying potentially harmful pollutants and studying their dispersion in the territory [2]. At the local scale, nitrous oxides $\left(\mathrm{NO}_{\mathrm{x}}\right)$ are commonly identified as pollutants of paramount interest, given their potential impacts on human health and ecosystems.

Local impacts of $\mathrm{NO}_{\mathrm{x}}$ related to the operation of $\mathrm{DH}$ networks represent the object of this work. This study considers the development of a methodology for calculating the environmental impacts of DH systems operation.

The results on $\mathrm{NO}_{\mathrm{x}}$ impacts of $\mathrm{DH}$ systems reported in previous studies can differ, depending on the size of the plant, the type of fuel and the operating conditions. Among the publications, a study by Brattebo and Reenaas [3], conducted on a waste to energy cogeneration plant, shows increased $\mathrm{NO}_{\mathrm{x}}$ emissions compared to an alternative scenario for waste management, as well as the need for advanced abatement technologies. Genon et al. [4] analysed the local impact of a future small DH system fuelled by natural gas engines. Their study considered two cases where 22 and 105 residential heaters were replaced with a CHP and DH system. The results indicated that the $\mathrm{NO}_{\mathrm{x}}$ emissions may in some cases exceed the existing emissions, although this aspect is strongly related to the type of conversion facility considered. Torchio [5] proposed an environmental and economic comparison of three different options: district heating, distributed generation and separate production of heat and power. The results for district heating option showed that the systems driven by microturbines and fuel cell technologies lead to a reduction of $\mathrm{NO}_{\mathrm{x}}$ emissions, while internal combustion engines did not show a local $\mathrm{NO}_{\mathrm{x}}$ saving.

This study analyses the environmental compatibility of intervening to expand the DH network in the urban area of Turin, in terms of local impact of nitrous oxides $\left(\mathrm{NO}_{\mathrm{x}}\right)$.

The Turin metropolitan area is currently in a leading position in the DH sector, having one of the largest networks in Europe [6]. Due to the persistence of critical concentration values of pollutants in the air of Turin, local administrations have for some years been exploring the possibility of obtaining an environmental benefit through the further extension of the DH network, removing centralized residential heaters.

\section{METHODOLOGY}

Local environmental impacts of $\mathrm{NO}_{\mathrm{x}}$ (as equivalent $\mathrm{NO}_{2}$ ) were studied for a one-year period. To this end, current emission scenario was analysed and a feasible energy and emission configuration was developed.

The first step was defining the energy balance in the study area. The flow of pollutants emitted by the sources was then estimated, and their dispersion was simulated implementing the CALPUFF dispersion model [7]. The latest available (related to 2014) power unit emission flow rates were used in this study; however, the meteorological input data sets collected in 2010 were used, because sufficiently accurate and complete data sets were not available for 2014. However, average meteorological conditions in the period 2010-2014 in the study area did not change significantly, so the approximation introduced is negligible. 


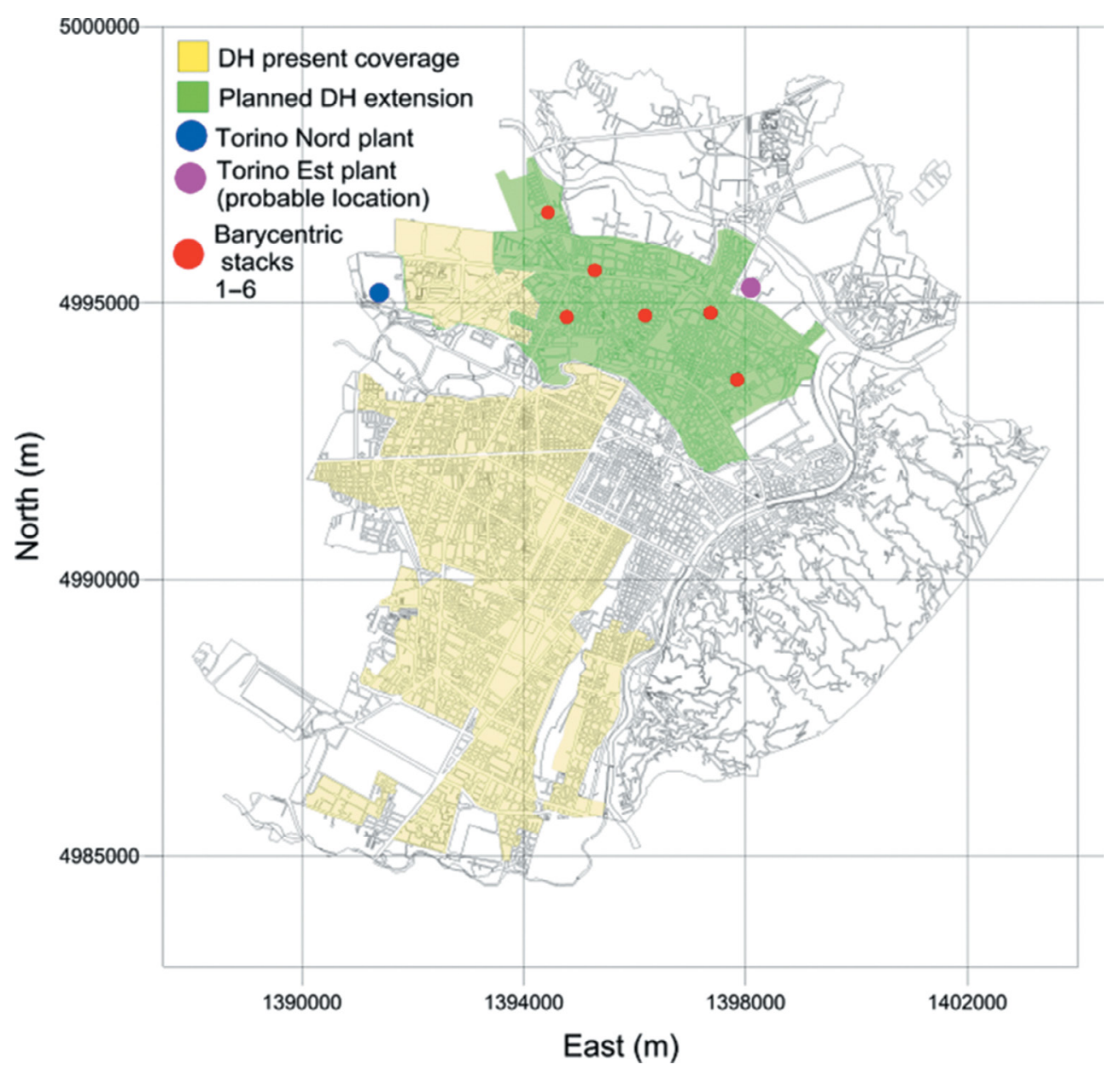

Figure 1: Current and planned extension of the DH network in the urban area of Turin. Location of the emission sources considered in the study. Coordinates system is UTM ED50 32T.

\subsection{Area of study}

The potential development of the Turin DH network covers the area reported in Fig. 1, which includes four districts of the northern and eastern parts of the city. The residential volume currently served by the DH network amounts to about 57 million $\mathrm{m}^{3}$, corresponding to approximately 570,000 inhabitants. The total extension of the network amounts to $527 \mathrm{~km}$. The development project involves approximately further 20 million $\mathrm{m}^{3}$. The thermal energy for this extra part of network is supplied by the Torino Nord (TO-N) plant, consisting of

- a combined cycle (CC) cogeneration unit fuelled by natural gas;

- four auxiliary boilers for integration and reserve, producing $85 \mathrm{MW}$ each, fuelled by natural gas;

- a heat storage system consisting of six batteries with a total capacity of about 5,000 $\mathrm{m}^{3}$;

- a system for pumping, pressurization, expansion and replenishing of the water in the DH network. 
Surface, volume and characterization of heating system (type of fuel, centralized or autonomous heating) data related to buildings in the study area were obtained from the 2001 Italian Census [8]. The data were extracted and processed using the Quantum GIS application.

\subsection{Present scenario (year 2014)}

The present emission scenario was developed considering the combined contribution of TO-N plant in its actual operating mode, and the residential area subject to the DH network extension. As a first step, the energy balance of each source was defined. Then, the emission flow of pollutants was calculated by applying the emission factors.

For the characterization of TO-N plant, two point emission sources were considered, one for the main stack of the $\mathrm{CC}$ unit and another for the four auxiliary boilers. Thermal energy produced by main generation unit and auxiliary boilers was calculated starting by hourly thermal power transferred to the DH network $\left(E_{\mathrm{tlr}}\right)$ that is directly measured by the continuous emissions monitoring system (CEMS) installed on the plant. The selected year was 2014, as it represents the latest data set available. Thus, the thermal energy produced by the boilers $E_{\text {cald }}$ was calculated by difference as

$$
\begin{gathered}
E_{\text {cald }}=E_{\mathrm{tlr}}-E_{\mathrm{tonmax}} \text { if } E_{\mathrm{tlr}}>E_{\mathrm{tonmax}} \\
E_{\text {cald }}=0 . \text { if } E_{\mathrm{tlr}}<E_{\mathrm{tonmax}}
\end{gathered}
$$

where $E_{\text {tonmax }}$ is the maximum thermal energy that can be transferred to the DH exchanger, namely $220 \mathrm{MWh}$. The flow of $\mathrm{NO}_{\mathrm{x}}$ emitted by the $\mathrm{CC}$ unit was also directly extracted by the CEMS. $\mathrm{NO}_{\mathrm{x}}$ emissions of auxiliary boilers were calculated by multiplying $\mathrm{E}_{\text {cald }}$ for the average emission factor declared by plant operator for 2014 (Table 1). TSP flow was instead calculated by applying EMEP/EEA emission factors (Table 1).

For the characterization of the emission flows of residential sources subject to the DH network extension, six homogeneous areas were defined, considering different types of buildings (period of construction, geometry) and population density. A barycentric stack was assigned to each area (Fig. 1). Heat demand of buildings was calculated by applying the model proposed by Fracastoro and Serraino [9], in which data of surface, number of floors, type of fuel (natural gas, diesel oil, LPG or heavy oil) and type of system (centralized or autonomous) are considered. This energy model returned the annual thermal energy need of single buildings. The annual figure was then multiplied by the hourly distribution of a benchmark building, i.e. using the real-time demand curve of a representative building, which is located in Turin and subject to a continuous measurement. Hourly thermal energy request was then multiplied by the corresponding emission factor (Table 1).

\subsection{Future scenario}

Future scenario was developed considering the connection to the DH network of the only buildings with centralized heating, considering an average commercial penetration factor. Annual thermal energy consumption of the six areas was then divided into a portion connected to $\mathrm{DH}\left(E_{\text {fut_tr })}\right.$ and a portion not connected to $\mathrm{DH}\left(E_{\text {fut_nottr }}\right)$ :

$$
\begin{gathered}
\text { fut-tlr }=E_{c e n} \cdot F_{p} E \\
E_{\text {fut-notr }}=E_{c e n} \cdot\left(1-F_{p}\right)+\mathrm{E}_{\text {aut }}
\end{gathered}
$$


Table 1: Emission factors of $\mathrm{NO}_{\mathrm{x}}$

\begin{tabular}{lcc}
\hline Emission source & $\mathrm{NO}_{\mathrm{x}}$ emission factor $(\mathrm{kg} / \mathrm{MWh})$ & Reference \\
\hline Torino Nord - combined cycle & 0.167 & {$[10]$} \\
Torino Nord - auxiliary boilers & 0.063 & {$[10]$} \\
Torino Est & 0.063 & - \\
Residential stacks (natural gas) & 0.180 & {$[11]$} \\
Residential stacks (diesel oil) & 0.180 & {$[11]$} \\
Residential stacks (LPG) & 0.180 & {$[11]$} \\
Residential stacks (heavy oil) & 0.540 & {$[11]$} \\
\hline
\end{tabular}

where $E_{\text {cen }}$ is the thermal energy requirement of buildings with centralized heating system, $F_{\mathrm{p}}$ is the average commercial penetration factor of 0.8 [12], and $E_{\text {aut }}$ it is the thermal energy requirement of the buildings with autonomous heating system. $E_{\text {fut_tlr }}$ and $E_{\text {fut_notr }}$ were then distributed on an hourly basis using the aforementioned methodology. The term $E_{\text {fut }}$ tr was subsequently added to the current demand $E_{\text {trr }}$, obtaining the required hourly thermal energy to be satisfied in the future operational mode $\left(E_{\text {fut_tot }}\right)$ :

$$
E_{\text {fut_tot }}=E_{\text {fut_tlr }}+E_{\text {tlr }}
$$

$E_{\text {tlr }}$ and $E_{\text {fut_tot }}$ terms in January are reported in Fig. 2. Peak values of $E_{\text {fut_tot }}$ reach around $900 \mathrm{MWh}$, going beyond the operational capacity of TO-N plant and its auxiliary boilers $(220 \mathrm{MWh}+340 \mathrm{MWh})$. For this reason, it was necessary to simulate the entry into service of a new integration and reserve system, able to satisfy the residual heat demand during peak hours. This system was identified in the Torino Est (TO-E) plant, a new generation group consisting of four integration boilers having a nominal thermal power of $85 \mathrm{MW}$ each, technically identical to those of TO-N plant. Indeed, to date there are feasibility studies in

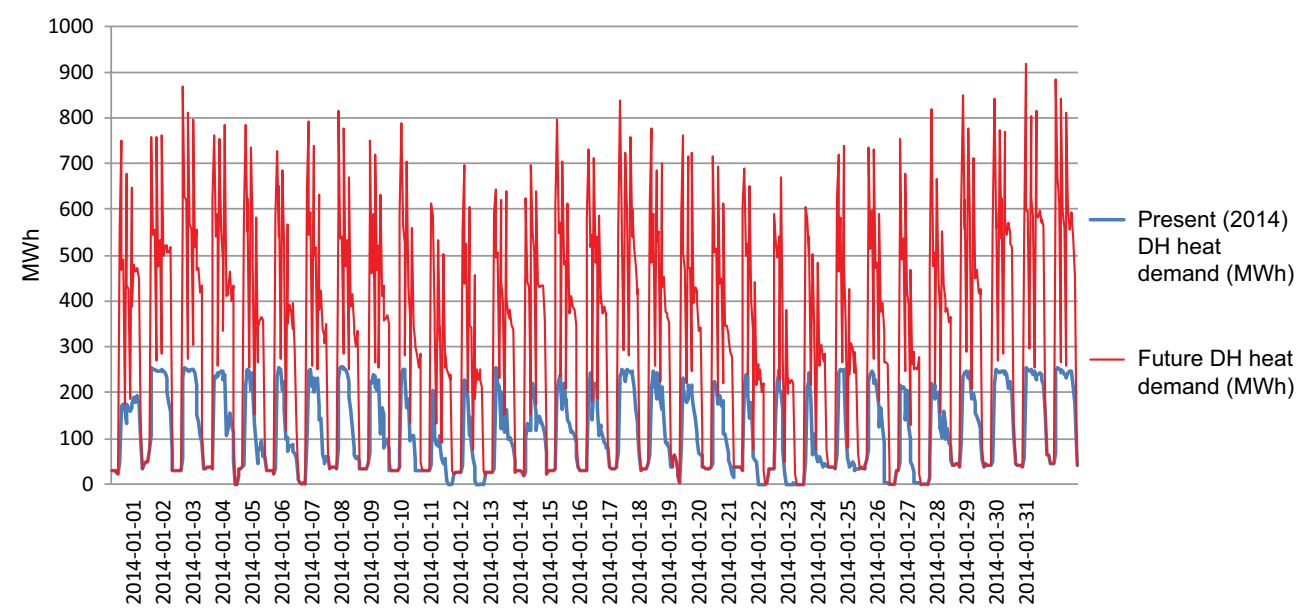

Figure 2: Hourly thermal power demand of the DH network in northern and eastern areas of Turin for the year 2014 (present scenario) and for future scenario, month of January. 
progress for the construction of this plant, that also identify a possible location in the area (Fig. 1, [12]).

Assuming the operation of TO-E plant, the future configuration of energy production was defined. The following heat dispatching priority was assumed: TO-N (combined cycle); TO-E; TO-N (auxiliary boilers). Hourly production curves of the three generation units were finally multiplied by the corresponding emission factors, obtaining hourly emission flows of $\mathrm{NO}_{\mathrm{x}}$. TO-E plant emission factors were assumed equal to those of TO-N auxiliary boilers (Table 1).

\subsection{Environmental balance}

The environmental balance of $\mathrm{NO}_{x}$ emissions was obtained by calculating the average concentration differences at ground level resulting from CALPUFF simulations. As previously reported, the present scenario considered the combined contribution of TO-N plant and buildings not connected to the DH network. The future scenario considered the combined effect of TO-N and TO-E plants, and buildings still not connected to $\mathrm{DH}$ after the intervention of extension.

To simulate the dispersion of $\mathrm{NO}_{x}$ in the scenarios considered, geophysical and meteorological input data were obtained from the Regional Agency for Environmental Protection of the Piedmont Region (ARPA).

Weather and orographic data covered a domain of $100 \times 100 \mathrm{~km}^{2}$ with a horizontal resolution of 1,000 $\mathrm{m}$. The same grid represented also the modelling domain. The domain extension was wider than the expected extension of dispersion impacts. This was done to consider the meteorological features of the area, because the surrounding orographic reliefs may indirectly affect the dispersion. The key parameters of the emission sources used in the simulations are reported in Table 2. The simulation was run on the entire heating season of the year, i.e. from October to March.

Table 2: Emission source parameters implemented in CALPUFF model.

\begin{tabular}{llcccc}
\hline Source ID & Description & $\begin{array}{c}\text { Height } \\
(\mathrm{m})\end{array}$ & $\begin{array}{c}\text { Diameter } \\
(\mathrm{m})\end{array}$ & $\begin{array}{c}\text { Exhaust gases } \\
\text { temperature }(\mathrm{K})\end{array}$ & $\begin{array}{c}\text { Exhaust gases } \\
\text { speed (m/s) }\end{array}$ \\
\hline TO-N1 & $\begin{array}{l}\text { Torino Nord - } \\
\text { combined cycle }\end{array}$ & $60^{1}$ & $6.0^{1}$ & $274^{4}$ & Variable $^{5}$ \\
TO-N2 & $\begin{array}{l}\text { Torino Nord - } \\
\text { auxiliary boilers }\end{array}$ & $60^{1}$ & $8.0^{1}$ & $274^{4}$ & $11.8^{1}$ \\
& Torino Est & $60^{2}$ & $8.0^{2}$ & $274^{2}$ & $11.8^{2}$ \\
TO-E1 & Bar. stack area 1 & $15^{3}$ & $0.8^{6}$ & $270^{6}$ & $5.0^{6}$ \\
TO-A1 & Bar. stack area 2 & 15 & 0.8 & 270 & 5.0 \\
TO-A2 & Bar. stack area 3 & 15 & 0.8 & 270 & 5.0 \\
TO-A3 & Bar. stack area 4 & 15 & 0.8 & 270 & 5.0 \\
TO-A4 & Bar. stack area 5 & 15 & 0.8 & 270 & 5.0 \\
TO-A5 & Bar. stack area 6 & 15 & 0.8 & 270 & 5.0 \\
TO-A6 & 15 & & \\
\hline
\end{tabular}

Notes: 1 Project data; 2 Assumed to be equal to Torino Nord auxiliary boilers; 3 Average building height extracted from Census data [8]; 4 assumed to be equal to the Moncalieri plant, for which the data of the CEMS is available; 5 Calculated on an hourly basis from the datum of flow of exhaust gases from the stack; 6 . Average data found in previous studies. 
Table 3: Changes in total $\mathrm{NO}_{\mathrm{x}}$ emission between present (year 2014) and future scenario.

\begin{tabular}{lcr}
\hline Emission source & \multicolumn{2}{c}{$\mathrm{NO}_{\mathrm{x}}(\mathrm{t} / \mathrm{y})$} \\
\hline TO-N plant & Present & Future \\
TO-E plant & 57.68 & 104.70 \\
Buildings not connected to DH & 172.47 & 57.49 \\
Buildings connected to DH & - & 114.98 \\
(avoided emissions) & & \\
Total produced emissions & 230.15 & 224.74 \\
\hline
\end{tabular}

Output data from CALPUFF were sent to CALPOST post-processor, obtaining hourly concentration grids. Subsequently, the creation of an algorithm in GNU Octave allowed the extraction and localization of the maximum and minimum values, the definition average monthly concentration grids and the reformatting of data in the form of concentration maps.

\section{RESULTS}

The overall environmental balance of the intervention considered, comparing the present and future annual mass flow of $\mathrm{NO}_{x}$, is reported in Table 3. The concentration maps resulting from the simulation of pollutants dispersion are reported in Figs. 3 and 4. The results of Table 3 show that the extension of the $\mathrm{DH}$ network would bring a reduction on total $\mathrm{NO}_{\mathrm{x}}$ emissions of around $5.4 \mathrm{t} / \mathrm{y}$, corresponding to $2.3 \%$ of actual emission.

The concentration values were obtained by simulating the aforementioned emission sources. The result of the environmental balance, in terms of $\mathrm{NO}_{\mathrm{x}}$ average concentration difference at ground level in the urban area of Turin, base case simulation, is shown in Fig. 3. The same result, extended to the entire modelling domain, is reported in Fig. 4. Positive and negative values indicate increased or reduced impacts, respectively, compared to the present situation. The result shows from 0.2 to $\mu \mathrm{g} / \mathrm{m}^{3}$ to $4 \mu \mathrm{g} / \mathrm{m}^{3}$ reduction of $\mathrm{NO}_{\mathrm{x}}$ concentration with respect to the present situation. Figure 4 indicates that local effects are mainly limited to the urban area and the concentration difference approaches zero in the surrounding.

The absolute maximum and minimum values extracted by the GNU Octave algorithm are reported in Tables 4 and 5. These tables show a strong variability of the concentration that depends mainly on pollutants emission rate and atmospheric stability conditions. Maximum (positive) values are the effect of the pollutant plume emitted by TO-N and TO-E plants, which affect the hilly areas surrounding Turin. Minimum (negative) values are recorded in the area interested by the DH network extension and are generated by low residential stacks emissions.

As a final step, the base case simulation was reproduced calculating the emissions of the six residential areas using an area source instead of a point source type. The result of the heating season average is reported in Fig. 5. It can be concluded from Fig. 5 that the contaminant removal is more dispersed over the area in comparison with point source simulations. 


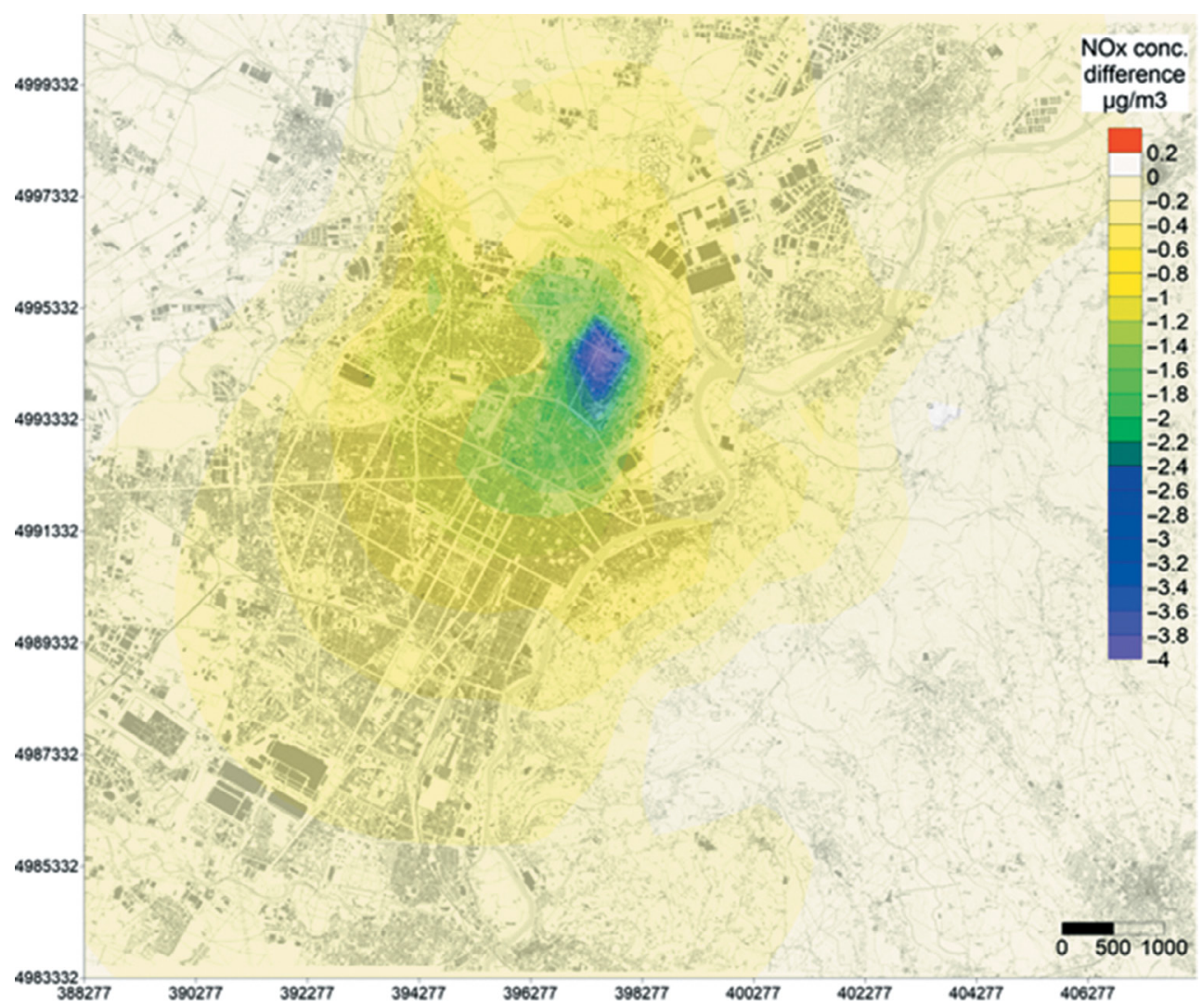

Figure 3: $\mathrm{NO}_{\mathrm{x}}$ average concentration difference at ground level between future and present scenariosintheurbanareaofTurin, basecasesimulation. Theaverageiscalculatedoverthe six coldest months of the year (October to March).

\subsection{Discussion}

The results show a general reduction of $\mathrm{NO}_{\mathrm{x}}$ presence in the urban area of Turin following the DH network extension. To evaluate the magnitude of this reduction, the reference monitoring station in the study area (Torino Rebaudengo) was considered. The annual average concentration measured by this station in 2014 was $70 \mu \mathrm{g} / \mathrm{m}^{3}$. This means that the interventions considered would bring to a maximum $\mathrm{NO}_{\mathrm{x}}$ reduction of $5.7 \%$ of the total concentration. These numbers demonstrate a significant result.

Of the aforementioned studies, in Genon et al. [4] two cases with 22 and 105 heating systems were considered and replaced with CHP and DH systems. In the first case, the average $\mathrm{NO}_{x}$ concentration in the calculation domain declined by $0.2 \mu \mathrm{g} / \mathrm{m}^{3}$; in the second case, an average improvement of $1.7 \mu \mathrm{g} / \mathrm{m}^{3}$ was reported.

It must be pointed out that uncertainty is inevitably high in this study, given the size of the system and the large number of factors involved. In particular, the precise characterization of the emission scenario (height of the sources and reproduction of the building profiles in their surrounding) has a significant importance. A possible future scope for this study might therefore be a more detailed reconstruction of the residential areas and their sources. 


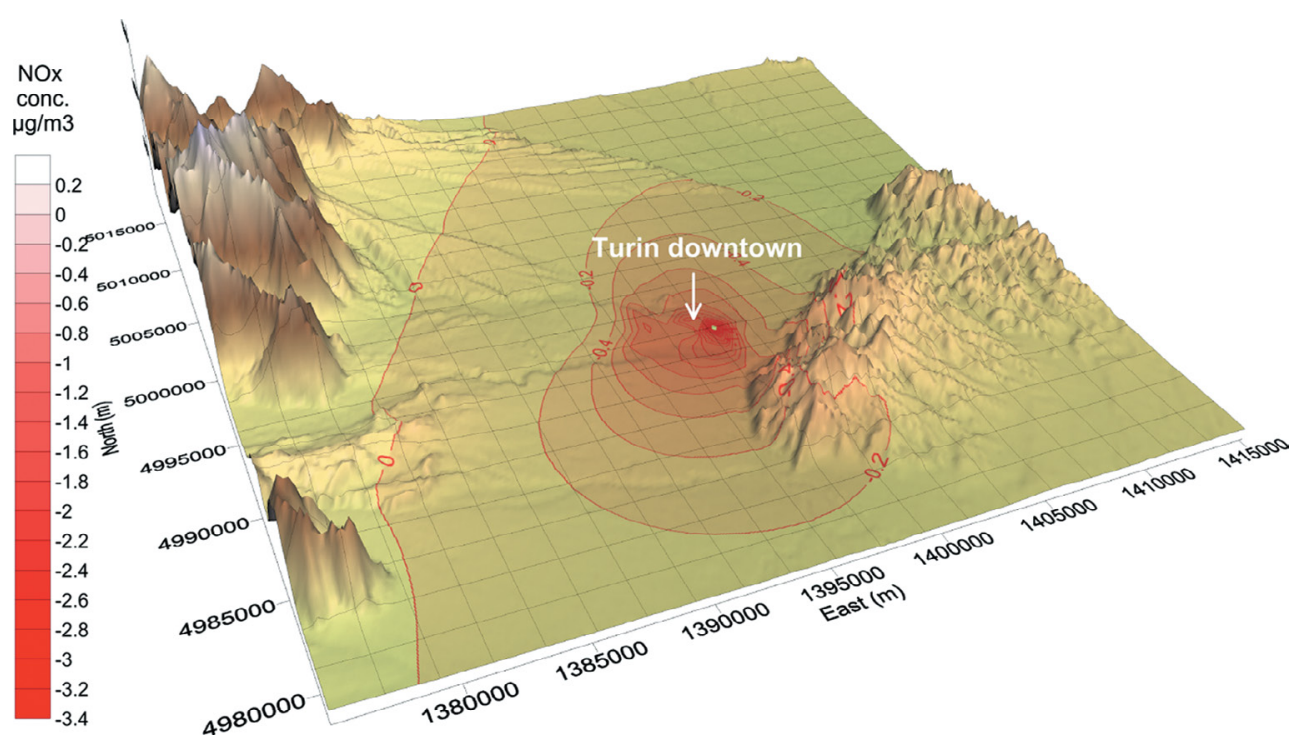

Figure 4: $\mathrm{NO}_{\mathrm{x}}$ average concentration difference at ground level between future and present scenarios in the entire modelling domain. The average is calculated over the six coldest months of the year (October to March).

Table 4: Maximum values of ground-level concentration with relative date and position extracted from the simulation of the future scenario.

\begin{tabular}{cccc}
\hline $\begin{array}{c}\mathrm{NO}_{\mathrm{x}} \text { maximum conc. } \\
\left(\mu \mathrm{g} / \mathrm{m}^{3}\right)\end{array}$ & Month / Day / time & East coord. $(\mathrm{km})$ & North coord. $(\mathrm{km})$ \\
\hline 63 & $02 / 0607: 00$ & $1,403.500$ & $4,993.500$ \\
59 & $01 / 3107: 00$ & $1,401.500$ & $4,989.500$ \\
50 & $01 / 3107: 00$ & $1,400.500$ & $4,989.500$ \\
\hline
\end{tabular}

Table 5: Minimum values of ground-level concentration with relative date and position extracted from the simulation of the future scenario.

\begin{tabular}{cccc}
\hline $\begin{array}{c}\mathrm{NO}_{\mathrm{x}} \text { minimum conc. } \\
\left(\mu \mathrm{g} / \mathrm{m}^{3}\right)\end{array}$ & Month/Day/time & East coord. $(\mathrm{km})$ & North coord. $(\mathrm{km})$ \\
\hline-270 & $12 / 0415: 00$ & $1,397.500$ & $4,994.500$ \\
-220 & $12 / 2211: 00$ & $1,397.500$ & $4,994.500$ \\
-212 & $01 / 0912: 00$ & $1,397.500$ & $4,994.500$ \\
\hline
\end{tabular}




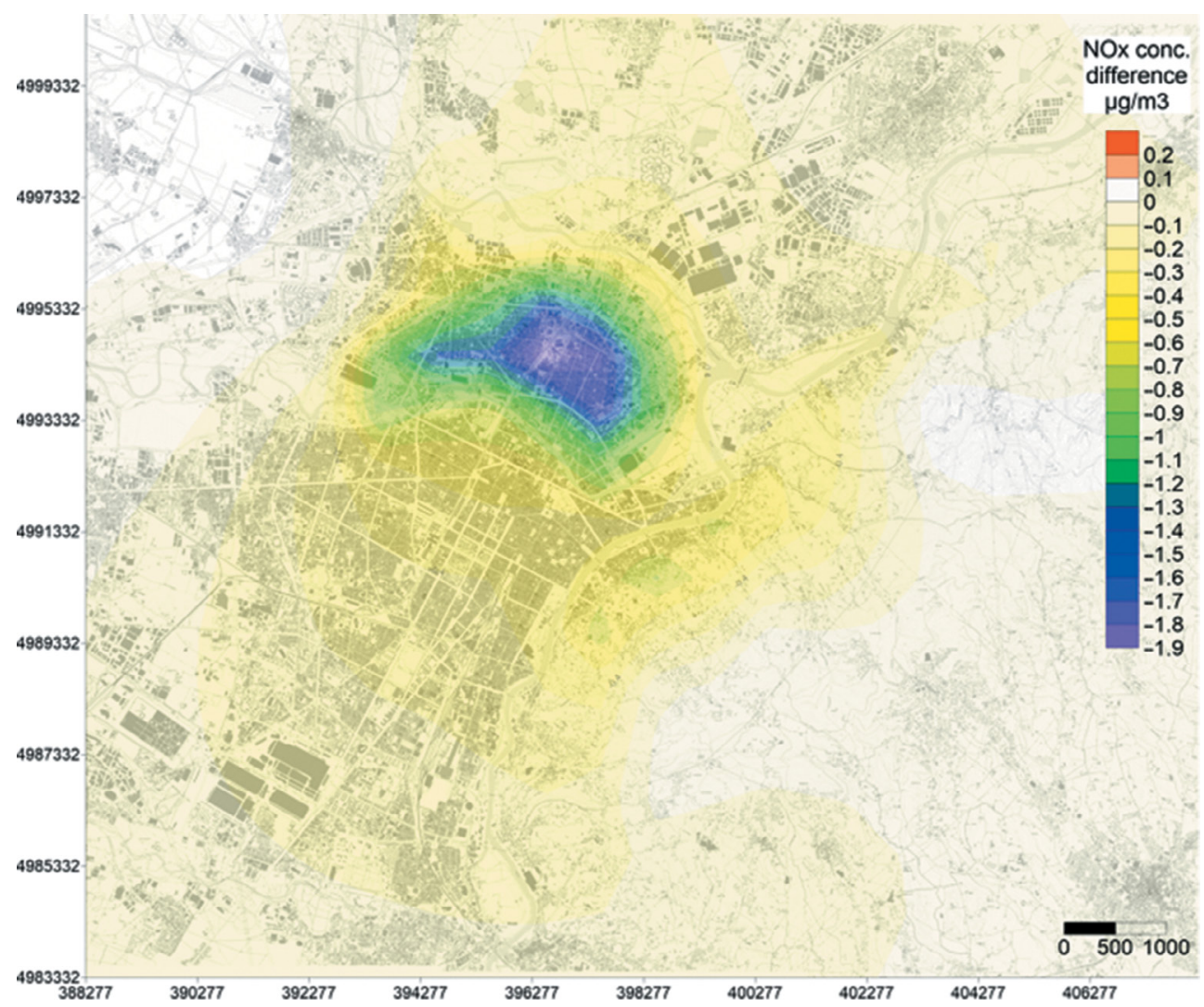

Figure 5: $\mathrm{NO}_{\mathrm{x}}$ average concentration difference at ground level between future and present scenarios in the urban area of Turin, simulating residential emissions as areas sources. The average is calculated over the six coldest months of the year (October to March).

The analysis of the state of the art confirms that the centralization of energy production brings the following advantages:

- a primary energy saving thanks to the improved efficiency of the system, as also reported by Finney et al. [13];

- more control and reduction of the emissions: the modern CC plants (like TO-N) are equipped with advanced abatement systems and CEMS supervised by both the operator and the public environmental control agencies [14].

The economic aspects related to the exercise of large scale cogeneration plants are currently under study. A part of this study concerns the effects of energy market constraints, that have been demonstrated to have an influence on the operation of these systems $[6,15]$. Another part of the study involves the characterization of external health costs associated to the DH system operation.

Implementing a largely consolidated model as CALPUFF resulted suitable to the magnitudes and scale of the study. The result of the environmental balance using area-type sources 
provided a more uniform concentration compared to the use of barycentric stacks, that is what it could be expected in the reality. On the other hand, the disadvantage in using areatype sources with CALPUFF is that the simulation of building downwash phenomena is not implemented.

Finally, the analysis of maximum and minimum values reveals a high variability of the average results due to the atmospheric conditions that may occur on the area of study. Turin is a scarcely ventilated city. The average wind speed obtained from the time series (1990-2005) is $0.9 \mathrm{~m} / \mathrm{s}$, while the average annual number of wind calm days is equal to 75 [16]. These factors foster situations of poor mixing and the formation of a stable urban boundary layer [17]. To obtain more information on the variables leading to peak concentrations, weather records in correspondence of maximum and minimum values were investigated. The coexistence of the following factors was observed:

- limited height of the mixed layer (below $100 \mathrm{~m}$ );

- positive values of the Monin-Obukhov length;

- low horizontal wind speed (below $2 \mathrm{~m} / \mathrm{s}$ );

- low air temperature (between $-2^{\circ} \mathrm{C}$ and $3^{\circ} \mathrm{C}$ );

- low total radiation (below $60 \mathrm{~W} / \mathrm{m}^{2}$ ).

\section{CONCLUSION}

This study reports the results of a survey on the local environmental effects of the potential extension of the DH network in the urban area of Turin. The results show that connecting part of the residential heating systems to the network produces an improvement to air quality in terms of $\mathrm{NO}_{x}$ concentration at ground level. The reduction of contaminants is highest around the area subject to the intervention (northern and eastern districts of Turin), with positive effects also extending towards the city centre. The average value of pollutant removal is estimated to be around $1 \mu \mathrm{g} / \mathrm{m}^{3}$, with a maximum between 2 and $5 \mu \mathrm{g} / \mathrm{m}^{3}$. The last Emission Inventory published by Piedmont Region in 2010 shows that road traffic represents the main source of $\mathrm{NO}_{x}$ emissions, contributing to around $50 \%$ of total emissions. Industrial energy production and residential heating sectors account for around $7 \%$ and $5 \%$, respectively. Considering these data, together with the analysis of annual emission flows reported in Table 3, the intervention object of the present study is not expected to bring a significant change in total emission of pollutants. On the other hand, if average concentrations are considered, a maximum $5.7 \%$ reduction for $\mathrm{NO}_{x}$ may be obtained. This value would undoubtedly correspond to an environmental improvement at the local level, in this heavily populated area subject to significant air quality issues.

Further considerations can then be made on the removal of obsolete boilers and the centralization of energy management. First, it is known that a centralized integrated system for energy production results in higher conversion efficiency, i.e. in a saving of primary energy. Secondly, large power units like TO-N are equipped with a continuous and precise monitoring system of air emissions, which is controlled both by the operator and by the regional Environmental Protection Agency. These undoubtedly constitute positive aspects for urban pollution control and mitigation.

In conclusion, this study provides important information on the effects on air quality resulting from the modification of the energy management of an area or settlement.

From a more general point of view, the methodological approach used in this study included the combined analysis of the energy scenario associated with heat generation and distribution 
in DH networks, and the calculation of the potential dispersion of pollutants connected to it, with the aim of quantifying and locating the potential environmental impact. It is therefore a consistent and comprehensive methodology, suitable to be reproduced and developed for other energy management case studies or applications, laying a valid foundation for subsequent technical and economic in-depth analysis.

Consequently, the instrument that has been elaborated is very important from the scientific point of view; in fact, by using the proposed methodology it is possible, based on the elaboration of data measured on site (or obtained from the operators), to acquire relevant information to define the general environmental situation of the examined area.

\section{REFERENCES}

[1] Lake, A., Rezaie, B., Beyerlein, S., Review of district heating and cooling systems for a sustainable future. Renewable and Sustainable Energy Reviews, 67, pp. 417-425, 2017. DOI: 10.1016/j.rser.2016.09.061.

[2] Ravina, M. \& Genon, G., Global and local emissions of a biogas plant considering the production of biomethane as an alternative end-use solution. Journal of Cleaner Production, 102, pp. 115-126, 2015. DOI: 10.1016/j.jclepro.2015.04.056.

[3] Bratteb $\varnothing$, H. \& Reenaas, M., Comparing $\mathrm{CO}_{2}$ and $\mathrm{NO}_{x}$ emissions from a district heating system with mass-burn waste incineration versus likely alternative solutions - City of Trondheim, 1986-2009. Resources, Conservation and Recycling, 60, pp. 147-158, 2012. DOI: 10.1016/j.resconrec.2011.11.001

[4] Genon, G., Torchio, M.F., Poggio, A. \& Poggio, M., Energy and environmental assessment of small district heating systems: Global and local effects in two case-studies. Energy Conversion and Management, 50, pp. 522-529, 2009. DOI: 10.1016/j.enconman.2008.11.010.

[5] Torchio, M.F., Comparison of district heating CHP and distributed generation CHP with energy, environmental and economic criteria for Northern Italy. Energy Conversion and Management, 92, pp. 114-128, 2015. DOI: 10.1016/j.enconman.2014.12.052.

[6] Jarre, M., Noussan, M. \& Poggio, A., Operational analysis of natural gas combined cycle CHP plants: Energy performance and pollutant emissions. Applied Thermal Engineering, 100, pp. 304-314, 2016. DOI: 10.1016/j.applthermaleng.2016.02.040.

[7] U.S. Environmental Protection Agency. CALPUFF Modeling System User's Manual, Version 6. U.S. Environmental Protection Agency, Emissions, Monitoring and Analysis Division (MD-14), Research Triangle Park: North Carolina, 2011.

[8] Istat, Italian Population Census, available at http://www.istat.it, 2011 (accessed 6 May 2016).

[9] Fracastoro, G.V. \& Serraino, M., A methodology for assessing the energy performance of large scale building stocks and possible applications. Energy and Buildings, 43, pp. 844-852, 2011. DOI: 10.1016/j.enbuild.2010.12.004.

[10] Iren Energia, Torino Nord Plant Continuous Monitoring System, available at http:// smetonord.irenenergia.it/tonord/default.asp, 2014 (accessed 20 April 2016).

[11] European Environmental Agency. EMEP/EEA, Air Pollutant Emission Inventory Guidebook. Technical Guidance to Prepare National Emission Inventories. EEA Technical Report, ISSN 1725-2237, Copenhagen, Denmark, 2013.

[12] Poggio, A., Maga C. \& Benedetti P., Pre-Feasibility Study for the Further Development of the District Heating Network Connected to Cogeneration in the Turin Area. Province of Turin, Italy. Report (In Italian), 2009. 
[13] Finney, K.N., Chen, Q., Sharifi, V.N., Swithenbank, J., Nolan, A., White, S. \& Ogden, S., Developments to an existing city-wide district energy network: Part II - Analysis of environmental and economic impacts. Energy Conversion and Management, 62, pp. 176-184, 2012. DOI: 10.1016/j.enconman.2012.03.005.

[14] Rezaie, B. \& Rosen, M.A., District heating and cooling: Review of technology and potential enhancements. Applied Energy, 93, pp. 2-10, 2012. DOI: 10.1016/j.apenergy. 2011.04.020.

[15] Åberg, M., Widén, J. \& Henning, D., Sensitivity of district heating system operation to heat demand reductions and electricity price variations: A Swedish example. Energy, 41, pp. 525-540, 2012. DOI: 10.1016/j.energy.2012.02.034.

[16] Fratianni, S., Cagnazzi, B. \& Cremonini, R., Wind in Piedmont Region. Series on Climate studies in Piedmont, Vol. 5. Piedmont's Environmental Protection Agency: Turin, Italy. (In Italian), 2007.

[17] Hanna, S.R., Briggs, G.A., Hosker, R.P., Handbook on Atmospheric Diffusion, Jean S. Smith Publication Editor, 1982. 